\title{
Decentralization and School Management in Namibia: The Ideologies of Education Bureaucrats in Implementing Government Policies
}

\author{
Hertha Pomuti ${ }^{1}$ and Everard Weber ${ }^{2}$ \\ ${ }^{1}$ National Institute for Educational Development, Ministry of Education, Okahandja 9000, Namibia \\ ${ }^{2}$ Department of Education Management and Policy Studies, Faculty of Education, Groenkloof Campus, University of Pretoria, \\ P.O. Box 20, Hatfield 0028, South Africa
}

Correspondence should be addressed to Hertha Pomuti, hpomuti@nied.edu.na

Received 3 January 2012; Accepted 6 March 2012

Academic Editors: D. M. Hoffman and J. Pedulla

Copyright ( 2012 H. Pomuti and E. Weber. This is an open access article distributed under the Creative Commons Attribution License, which permits unrestricted use, distribution, and reproduction in any medium, provided the original work is properly cited.

This paper defines ideology as the belief systems, attitudes, views, and mindsets of educationists which inform their work. It examines the ideologies of school inspectors, principals, and teachers in the implementation of decentralized, cluster-based educational change in Namibia (see Pomuti 2009). Data were collected in three diverse school clusters. Data analyses resulted in the ideologies of the educationists being characterised as authoritarian, bureaucratic, and managerial. The paper argues that while the postapartheid Namibian government has changed the governance structures in education, it has not succeeded in changing the mindsets and actions of important reform implementers. These have more in common with the apartheid system than with the participatory, collaborative, and democratic ideas upon which cluster-based school management in the new Namibia is based.

\section{Introduction}

Debates over the value and effects of decentralizing education governance to individual schools have been underway internationally for at least two decades. Recent school management initiatives in Namibia are instructive with regard to both these debates and the literature on school-based management and help to illuminate how the ideologies and actions of education bureaucrats determine the extent to which democratic forms of education governance are able to put down roots.

The advocates of decentralization assume that shifting authority and management responsibilities to local levels will promote effectiveness and efficiency in the use of resources in education $[1,2]$, make public education more responsive to local needs [3,4], and enable teachers and schools to exercise greater professional autonomy [4-6]. Critics have questioned these claims by drawing attention to the national and local circumstances which impede successful implementation $[2$, 7-11].
School-based management (SBM) focuses on decentralization at school level. SBM has been adopted as a strategy to increase school autonomy and to devolve decision making to teachers and sometimes to parents, students, and community leaders [12]. As with decentralization, SBM assumes that "those who are closest to the primary business of schools will make the best-informed decisions" [13]. Different countries use different terms to describe SBM. In Namibia the term "school clustering" is sometimes used instead of SBM. School clustering has been implemented on the assumption that teaching and school management will improve through sharing resources, experiences, and expertise among teachers [14-16]. The objectives of school clustering in Namibia are to improve school management, school supervision, and teaching and learning. The reform assumes that these goals will be achieved through shared, collaborative leadership and collaborative learning networks among teachers. It also promises to empower schools in decision-making processes and extend democracy in education [17]. 
There is considerable overlap between the goals of decentralization, SBM, and school clustering. Grant-Lewis and Motala [18], citing the Universal Declaration on Democracy, write "[d]emocracy and democratic participation are very much part of the decentralization discourse." Democracy provides an overarching conceptualization that can include SBM and decentralization.

Namibian principals are represented in clusters, that is, the management of different schools that are geographically close to one another are linked together in local management structures. As a result individual schools do not have real autonomy. Policy assigns greater authority at the regional, circuit, and cluster levels than at the level of SBM. The rationale for granting clusters more power than SBM was that the government wished richer schools to share resources with poorer schools, and schools with weaker managements to benefit from relationships with better-managed schools [19].

This paper examines how the ideologies of key education role players influence the implementation of cluster-based school management in Namibia. The empirical material, more so than the particular analyses and discussion presented here, is based on Hertha Pomuti's [20] doctoral thesis, supervised by Everard Weber. Drawing on the work of Mannheim [21], ideologies are viewed in relation to social and educational change. Mannheim studied the connections between interest groups in society and the ideas and values they articulated and argued that their ideas underpinned social actions in maintaining the status quo, or in bringing about change. Ideology is therefore not separated from political action. This paper therefore defines ideology as the belief systems, attitudes, views, and mindsets of educationists that inform and guide their work. Before analysing the ideologies of the implementers of recent decentralization reforms in Namibia, however, it is necessary to first survey the features of the system that the Namibian government wished to change.

\section{Apartheid Education Governance}

Following the defeat of Germany during World War I, South Africa was granted a United Nations mandate to govern what was then called South West Africa, effectively turning the territory into a province of South Africa. In 1948 the National Party won the whites-only elections in South Africa and proceeded to implement its policy of apartheid, dividing both countries along racial and ethnic lines, under white hegemony. Resistance to South African rule led to Namibian independence in 1990.

Apartheid education governance was characterised by racial and ethnic segregation and inequality, undemocratic participation, low levels of bureaucratic accountability and transparency, and top-down policy implementation, with power largely centralized to protect white privilege. In 1980 ten ethnic education authorities were created in Namibia, each establishing its own Directorate of Education, though whites retained key administrative positions and ultimate power was centralised in the Department of National Education. Limited decentralized administrative control was assigned to the ethnic structures, effectively making them satellites of the centre. Curricula in schools and teacher training colleges taught the apartheid ideology of segregation in accordance with "Christian National Education." Pedagogy consisted of teacher-centred, authoritarian, transmission instruction, with heavy reliance on officially approved textbooks and rote-learning, and assessment mainly by means of tests and examinations $[22,23]$. The defining characteristics of education governance were therefore complemented by the tenets of "Christian National Education," and these belief systems became part of the national culture, despite the resistance to apartheid by the black majority and also, as we shall see, despite independent Namibia's attempts to dismantle them.

\section{Implementing School Clustering}

After independence, a unified system of educational administration and management was established. Racial and ethnic forms of education governance were abolished, but local management structures continued to act as agents of the centralized structures.

Cluster-based school management was introduced in 2000. School clusters are authorised to manage school supervision and in-service training for school managers and teachers in order to improve management, equity, teaching, and learning, provide teacher support, and promote democratic participation. Clusters also have to ensure communication and collaboration between circuit offices and among schools and teachers. The head office and regional education offices are required to "give consistent support to circuit and cluster management levels about their responsibilities" [19].

Between five and seven schools are grouped into geographic clusters. One school in each cluster is the cluster centre, based on the fact that it has more resources, is accessible to satellite schools, and has access to commercial services. Each cluster has a cluster management committee, consisting of the principals in the cluster, selected teachers and school governing body members, and headed by the cluster centre principal (CCP). The CCP is selected on the basis of his or her management and leadership skills, commitment and vision, and is responsible for coordinating the activities, management, and supervision of the school cluster. The CCPs were prepared for their new roles by the Basic Education Project which spearheaded the roll out of the reform. At the same time, cluster subject groups, consisting of teachers, were formed.

Three or four clusters in the same geographic region are grouped into circuits. Each circuit has a circuit management committee consisting of the circuit inspector and the CCPs. Circuit inspectors are the main facilitators for the implementation of the reform at the cluster level and also provide support and guidance to the CCPs [19].

School clusters serve as deconcentrated units of district education offices, responsible for administrative tasks which are centralised at the district, regional, and national levels. There is no real autonomy at the local or SBM level and education governance remains bureaucratic and hierarchical; in these respects there are similarities with the apartheid system. While efforts were made at the start of the reform to build 
the capacity of education officials - in the form of workshops for circuit inspectors and principals with titles like "Introduction of a decentralized education management and delivery system," and peer-coaching programmes aimed at building a new collegial culture among principals and teachers-it is clear that the ideological changes needed to match the reforms cannot be achieved within a short period. They require sustained programmes, support systems for educationists, and resources which, to date, the government has been unable to provide.

\section{Research Methods}

The questions that guided this study were developed deductively from a survey of the literature mentioned in the Introduction. These questions are as follows. What beliefs and views do education role players in Namibia have about cluster-based school management? How do these beliefs influence their work and the implementation of the reforms? Have their perceptions and work practices changed or remained the same? Have the reform goals been achieved?

Five of the 13 regions into which Namibian schools are grouped for administrative purposes have implemented the reforms for four or more years, and these regions were targeted for study. A questionnaire-based survey obtained basic data about the schools and the implementation of the reforms. Analysis of this data together with discussions with regional and district officials highlighted three criteria which appeared to have influenced the reforms and/or were important in understanding the reform context: geographic location, the socioeconomic conditions of the surrounding communities, and the role of leadership, that is, strong or weak management and commitment in driving change [20].

On the basis of these criteria, three school clusters with varying characteristics were selected for more in depth study. Makalani cluster has the most resourced schools, is situated in an urban area, and is led by strong leaders. Hendrich cluster has one well-resourced school, in a semiurban area, with a strong leader who was also tasked, according to education officials, with assisting the under-resourced schools and weaker leaders in the cluster. Otjimue cluster, by contrast, has many under-resourced schools and is situated in an impoverished community in a remote rural area [20].

Of the eight schools in Makalani cluster, four were chosen at random; of the five Hendrich schools, three were chosen (the well-resourced school and two others chosen at random); and of Otjimue's five schools, three were chosen at random. Semistructured interviews were then conducted with the principals of all ten chosen schools, with the two circuit inspectors (Hendrich and Otjimue clusters were both supervised by one inspector and Makalani cluster by another), as well as with ten Makalani, four Hendrich, and four Otjimue teachers with the longest teaching experience in primary schools [20].

The primary data source for this paper is the verbatim transcriptions of interviews, supplemented with insights from random focus group discussions and meeting observations. Interviews were coded, codes were grouped, and themes, generalizations, and analytic categories were developed. For instance, the category, "bureaucratic mindset," which refers to one of the three educationist ideologies discussed below, describes a network of interrelated themes: "division of labour," "top-down policy implementation" and "technicist beliefs". The method of data analysis was primarily inductive and grounded in the data. This did not preclude continuous iteration between the "steps" and interpretation and meaning-making throughout the process.

\section{The Ideologies of Educationists}

The outcome of the data analysis was the categorization of the educationists' ideologies as authoritarian, bureaucratic, and managerial. These ideologies framed their work practices and how they implemented the school cluster reform. It was found that the ideologies did not vary substantively across the three case study clusters; in fact, they were very similar. According to the educationists, the main factors determining reform outcomes were limited resources, distance and transport in rural areas; support systems and training for teachers and principals; principals' resistance to interference in the daily management of their schools; and reluctance by resourced schools to assist poorer, neighbouring schools.

5.1. Authoritarianism. Respect for and submission to hierarchical control characterized the authoritarian thinking of the respondents. This authoritarianism is opposed to individual and collective freedom of thought, initiative, and action and discourages local educationists' participation in decisionmaking processes.

The inspector responsible for the Hendrich and Otjimue school clusters imposed change upon schools and expected schools to implement change through submission to authority. There was little if any independent input from schools and teachers. He stated

Satellite school principals have to accept that cluster-centre principals have supervisory capacity... therefore we do not have cases of principals who don't respect the authority of the cluster-centre principals... in our circuit management meetings we talk about these things... we define the roles of cluster-centre principals (emphasis added).

The circuit inspector responsible for the Makalani cluster expressed reservations about the delegation of authority and responsibilities to CCPs because he interpreted such delegation as undermining his authority. He said

I don't delegate tasks to cluster-centre princi$\operatorname{pal}[\mathrm{s}]$, he already has his workload as a principal; this is an added responsibility. To devolve tasks and responsibilities to him... make[s] me uncomfortable. This disturbs the line of reporting to the appropriate authority.

Authoritarian control dominated the practices of school principals and teachers. The principals and teachers implemented the reform as a way of conforming to the orders from 
the head office, waiting for whatever instructions emanating from the central authorities.

Teachers do not like to go to meeting[s] because they do not learn... much... but they have to go because it is [a] ministerial order (Teacher, under-resourced school, Makalani).

Teachers discuss [a] lot of problems at cluster meetings, but they did not receive instructions from the central authority on how these problems can be solved (Principal, Hendrich).

We don't do a lot during the gathering; we do not know how to go about [implementing the policies]... we need to be guided on what to do (Teacher, resourced school, Hendrich).

We are not really working well as we were supposed to do... we do not have guidelines on how to manage the cluster. The CCP give[s] us some ideas when she visit[s] clusters and advise[s] us on how to improve our schools (Principal, Otjimue).

Teachers lack initiative to adjust the implementation of the changes to suit their particular circumstances. Teachers respect authority and line management. They attend cluster subject meetings although they state that they do not benefit much from these discussions. The management reform assumes that school principals and teachers will come up with innovations to improve teaching because the responsibilities of improving school management and teaching are delegated to clusters and schools. However, school managers do not involve teachers in the planning of cluster-based subject meetings, and teachers are given little or no opportunities to plan professional development activities, being simply instructed to attend the meetings.

While the reform advocates shared decision making, collective problem solving, and collaborative management, there was little or no teamwork in the three clusters. Inspectors managed the schools without consulting school principals, and the CCPs organized the cluster activities without involving the satellite school principals and teachers in their clusters.

Authoritarianism rests upon the tacit consent of teachers and school principals who accept the passive roles they are called upon to play and do not criticise the management styles of the more powerful officials. This applies especially to the Hendrich principals, who felt marginalised by the fact that only the CCP managed the cluster activities. Their responses in interviews show that while they recognise and dislike authoritarian management, this does not translate into vocal or overt resistance, or into the formulation of alternative or revised practices that, in theory, are supposed to occur. In turn this creates an enabling ideological environment and context for the bureaucratic mindset and practices discussed next.

5.2. The Bureaucratic Mindset. Hierarchy and specialised divisions of labour are key characteristics of the thinking categorised here as the bureaucratic mindset. Another important feature is that initiatives and policy directives come from the top and move more or less step by step down the ladder of authority to the local level. This mindset is also characterised by the technicist belief that schools, and organisations should be governed by rules, regulations and procedures; a practical consequence of this is that much time and effort go into completing documentation required by district and national offices.

The data revealed that inspectors, school principals, and teachers ignored democratic practices or continued operating as they did prior to the introduction of the new policies, implementing cluster-based school reform using bureaucratic methods. The Makalani inspector rejected the idea of allowing CCPs to act on his behalf. He regarded it as "un-procedural for the cluster-centre principal to be an acting inspector in my office ... and therefore the clustercentre principal must be at his school." The inspector believed in a hierarchical style of management and a clearly defined division of labour. It was therefore "unprocedural" for the school principal to perform the tasks of the circuit inspector.

Schools report directly to me, I do not allow cluster-centre principals to work in my office. The appointment of cluster-centre principals who are at the same level as other principals to supervise schools disturbs the line of authority.

On the other hand, the inspector responsible for the Hendrich and Otjimue clusters did delegate administrative tasks to CCPs, viewing the reform as a means of distributing administrative tasks among schools. However, although she thought that the CCPs had a responsibility to carry out administrative tasks in the cluster, and embraced the participatory styles of management implicit in the school reform, this inspector still expressed faith in bureaucratic control. She argued that she had to control the work of the CCPs, and that the CCPs in turn should control the work of the satellite school principals. She stated "they have to check and control the reports from other schools, the school statistics, and I will also control these in my office." Central to her perception of her job was the collection of information and the completion of forms required by the Ministry of Education.

In general principals and inspectors spent hardly any time on instructional leadership. The main task of the inspectors was to gather information and to implement the decentralization reforms through well-defined, linear processes.

We do not have satellite school principals in my circuit who are not clear about the roles and responsibilities of cluster-centre principals. In our meetings we define the roles and responsibilities of cluster-centre principals. We have given cluster-centre principals extra power over the satellite school principals. Cluster-centre principals have the authority to assign tasks to satellite school principals... they have to carry 
out the instructions from the cluster-centre principals because they are their superiors.

The Makalani inspector refused to delegate administrative tasks to the cluster, while the Hendrich and Otjimue inspector employed bureaucratic control in supervising the work delegated to the cluster level. The inspectors in effect discarded the reform's formally-stated, collaborative and democratic management modus operandi.

Like the inspectors, the school principals and teachers also clung to bureaucratic doctrines. Thus the Makalani CCP excluded the satellite school principals from the planning of the cluster activities. He was the only one who planned such activities: "when there is something that needs to be discussed... the secretary [and I] meet, plan and set up an agenda and other principals just attend the meeting."

The Hendrich CCP managed the decentralization innovations according to the instructions of the circuit inspector. The circuit inspector instructed the CCPs to exercise authority and power over the satellite school principals, and the CCPs took the responsibility for administering the cluster activities with little involvement of the satellite school principals. Although the cluster had created a year plan and formal structures for the coordination of cluster activities, the CCP in the Hendrich cluster organized the coordination and reporting of the cluster activities: "I have to visit satellite schools ... I have to check school statistics from other schools and send these to the circuit office and write monthly report[s] on cluster activities."

The power and responsibility of managing the cluster activities is vested in the CCP, a task she took seriously. She had to supervise the work of the satellite school principals. The Otjimue CCP also took control of the management of the cluster activities, because she believed that she had power and authority over the satellite school principals. She was meticulous about defining her role and outlining her responsibilities.

I am responsible for distributing information, check[ing] statistics of other schools, coordinating of ordering of [stationery] and materials of schools, reporting back to principals on developments, writing and submitting cluster reports to the inspector, coordinating activities in the cluster and arranging cluster meetings.

Although the Makalani satellite school principals regarded the management reform as having the potential to provide opportunities for collaboration among schools, they believed that initiatives and directives on how to facilitate the implementation process should come from the top and that there should be a more precise division of labour and better job descriptions.

The former cluster-centre principal gave us some guidelines... he explained to us what we [are] supposed to do... I know I have to advise teachers... the current cluster-centre principal is not really clear on what to do... what the clustercentre principal should do and what satellite school principals [are] suppose[d] to do... we need more clarity (Principal, Makalani).

There is a strong belief among the satellite school principals that the CCP should provide guidance as to what they must do. "Guidance" becomes synonymous with specific instructions. They expressed a preference for hierarchical styles of management and well-defined roles and responsibilities for CCPs and satellite school principals. Several satellite school principals said that initiatives should come from the CCP, being at the top in the management of the cluster activities. The bureaucratic styles of control and faith in the virtues of line management facilitated the creation of dependency in decision making, not initiative-taking.

5.3. Managerialism. Educationists' beliefs in managerialism are based on concerns for efficiency, cost-effectiveness and competition. While the bureaucratic mindset stresses managing institutions by rules, regulations and procedures, managerialism draws attention to the specialised skills and techniques required by the managers. Although competitiveness and pursuing individual rather than group interests decreases the prospects of collaboration, they were perceived to be part of promoting efficiency.

The inspector responsible for the Hendrich and Otjimue clusters regarded the management reform as a means of improving poorly-organized schools and empowering school principals: "I see the system as a means of trying to put the management of weak schools on certain standards ... therefore we assist our principals during cluster management meeting $[\mathrm{s}]$... we should educate them." Similarly, the Makalani CCP interpreted the reform as a function of improving the administrative efficiency and effectiveness of schools.

... [the] clustering system is supposed to be an effective school administration through networking and sharing of information and expertise, and requires the commitment and cooperation of every principal in order to [build] a strong team for decision making and the willingness to work hard to enhance the improvement of the quality of teaching.

According to this CCP the reform could improve the management skills of the school principals. He said that knowledge, skills, and commitment to making the policy a success were important factors in implementation and that the reform had the potential to improve the quality of teaching. However, it was not made clear exactly how this would take place. As noted above, teachers did not find the cluster subject meetings meaningful in enhancing classroom practices. Observations during all the cluster meetings during the fieldwork as well as the testimony discussed below suggest that specific intervention programmes that are aimed at management and teaching and that are followed through at schools and in classrooms might work better than discussions about the reform's broad goals. The knowledge and skills referred to by the Makalani CCP appears to consist more of technical expertise than, for example, the ability 
to deal with the web of social relations at schools. Managerialism in this sense, that is, managing the acquisition of appropriate technical skills, is limiting because it closes rather than opens up critical debate about public policy on education governance in postapartheid Namibia.

The satellite school principals were encouraged to compete among themselves. They believed they could work on their own, without the support from other schools. The desire to be self-sufficient was a key feature of how schools in the richer urban cluster responded to the introduction of cluster-based management. The inspector responsible for this cluster, the Makalani cluster, commented on the selfadequacy of the satellite schools as follows.

The system in this cluster is not working properly. I do not know... there is a strong competition between schools... the schools find it difficult to cooperate ... you know... almost all schools in this town are on par in terms of strong leadership and resources. School principals have been reluctant to accept the authority of another principal... there was strong competition among the schools in the cluster and the schools did not cooperate effectively.

One of the satellite school principals commented as follows on the inadequacy of the reform to improve the management of her school.

[the] cluster system did not influence the management of my school... it did not upgrade my managerial skills... one workshop was held... the cluster-centre principal does not provide support to school principals... he does not have information on how to manage the cluster (Principal, Makalani).

The satellite school principals in Hendrich cluster also viewed the reform as having the potential to provide opportunities for improving the management of weak schools: "it is a system of grouping weak schools with strong schools so that the weak schools can benefit from strong schools." However, the satellite school principals believed that they should be given the opportunity to participate in the management of the cluster activities.

...our ideas are that each principal has a responsibility in the management of the cluster, we have to be part of the management of the cluster and not only one principal (Principal, Hendrich).

...we are not really involve[d] in the management of the cluster, the CCP is the only one who coordinate[s] the cluster activities; we do not want the CCP to manage the cluster alone (Principal, Hendrich).

These principals felt disempowered, resisted the management styles of the CCPs, and showed low commitment to implementing the reform. The satellite school principals in the Hendrich cluster believed that they should be given the right to manage their own schools: "the cluster system did not change the way I manage my school... you see we are also principals of our schools, we have skills to manage our schools." School principals appeared to be accustomed to individualism and independence in the organization and management of their schools and resisted interference in their authority to run their schools as they saw fit on a daily basis. The managerial autonomy of principals is closely linked to know-how about mastering the appropriate techniques that can assist them. There is an expectation that decentralization ought to provide opportunities for such learning and capacity building, and it is criticised for not having done so.

The concerns above, about whether or not "weak" schools can be assisted by "strong" schools, or how regularly the clusters meet, or whether skills can be sharpened through decentralization, ignore the more problematic meanings and practices of managerialism. They tend to focus on how well or poorly the reform has been implemented rather than whether or not it should have been implemented at all or what the alternatives are.

The satellite school principals in Otjimue cluster, like their colleagues elsewhere, also viewed the school management reform as having the potential for improving the management of rural schools.

[the] cluster system could help rural schools to perform better because the resources are near and teachers need to be encouraged to work together.

[the] cluster system is a good system... if strengthened it will improve the standards of schooling in rural areas.

These school principals in Otjimue, however, made the point that the provision of more resources to rural schools was critical. As the implementation process unfolded, they realised that the system might not be sustainable because of limited resources. They cited the following issues which were linked to limited resources: "the meetings are not held regularly because of distance and transport"; "there is no visit from the cluster-centre principal because of transport problems"; and "there are limited funds to sustain the cluster activities".

Teachers in the richer and semiurban clusters could not work in a collaborative manner. As in the case of satellite school principals in Makalani and Hendrich clusters, the teachers from resourced schools were satisfied with their situation. They were individualistically-oriented and not concerned about their colleagues elsewhere. The teachers, especially from the Hendrich cluster, believed that they could improve their teaching practices without the interaction of teachers from other schools: "our own teaching practices will improve more without the rest of the cluster.... If schools have different surroundings [circumstances], can they really [be] interactive [with us] in a positive way?."

On the one hand, teachers from the better resourced schools maintained that the reform does not have any 
benefits for them. They also said that there is no cooperation from other teachers in the cluster and therefore argued that the reform had not promoted collaboration and cooperation among teachers. They preferred to remain self-sufficient in terms of resources and to work on their own. A teacher from one such school in the Hendrich cluster said "as a cluster centre, we find that the teachers from other schools, who really need help, are not interested... sometimes it is so tiresome to try to drag them along. . . [at] the expense of your school."

On the other hand, teachers from under-resourced schools maintained that although the reform provides opportunities for teacher collaboration and learning, its effectiveness and efficiency depends on its ability to provide clear guidelines on how to support teachers learning from one another. The CCP in Hendrich said "we do not have confidence in the school clustering system... we receive little from other schools... we do not benefit from the system." The complaint about the unproductive nature of what transpires at cluster-based subject meetings was raised once more.

The fact that the reform does not have a clear focus on how to support teachers to improve their teaching practices promotes indifference to the reform among teachers from under-resourced schools, particularly in the Hendrich and Makalani clusters. Schools have become accustomed to working in isolation and in being competitive and individualistic. They have not adapted to the values and practices of collaboration and cooperation. It is evident that the resourced schools in the Makalani cluster and the resourced school in the Hendrich cluster have found it difficult to accommodate the under-resourced schools because they feel self-sufficient and continue to protect their resources.

\section{Conclusion}

The Namibian school clustering reforms have had limited success. While the formal governance structures have changed significantly, the thinking and actions of important implementers have remained the same. Whereas the new reforms are based on collegiality and participatory democracy, the apartheid era reverence for authoritarianism, hierarchy and bureaucracy has not changed. The ideologies of Namibian education bureaucrats have determined how policy translates into practice. The empowerment and autonomy envisaged by school clustering has been constrained by the decisive roles the central Education Ministry and its regional officials continue to play. Additionally, the actual conditions under which transformation occurred determined limited policy outcomes across the three different clusters.

The authoritarian, bureaucratic and managerial ideologies are intertwined and complement one another. For example, technical rationality privileges the execution of tasks. This should be distinguished from critical, intellectual evaluations of what meanings underpin practical work. Several respondents criticized the reform because they said that, while it had the potential to provide them with the managerial skills required to execute their work better, it had failed to do so. Others complained about the vague definitions of job descriptions, roles and responsibilities, and the degree to which bureaucratic line-management functioned smoothly. In theory, to demand a greater say in decision-making by, for example, setting agendas for meetings, does not necessarily mean a change in substance, that is, what will be debated, whose voices are heard, and whose might be silenced. Some respondents said there had to be more efficient administration - through more specialized division of labour, more resources, and greater capacity building within the clusters. Through technical rationality, authoritarianism and tacit consent lower down the bureaucratic ladder are likely to be consolidated. The education bureaucrats interviewed for this study advocated improved reform outcomes in accordance with old paradigms. Instead of instrumental rationality, one could foreground the intellectual underpinnings of policy implementation and strengthen the elements that might extend democratic education governance. This would be consistent with the policy goals of cluster management that seek to create informed, active participants and deepen the quality of decision-making.

That the old mindsets have not really changed means that the degree of democracy has been constrained at the local level. Decentralization and macro education policy more generally are not critically discussed at meetings and in the cluster structures. Several respondents made the point that there are no specific programmes through which the democratic goals of cluster management can be achieved. In effect, the post-apartheid state in Namibia has introduced a reform that in theory is meant to empower the grassroots from the top down, but has provided no mechanisms that might enable regions, districts and schools to change government policy from the bottom up.

\section{References}

[1] J. Ainley and P. McKenzie, "School governance: research on educational and management issues," International Education Journal, vol. 1, no. 3, pp. 139-151, 2000.

[2] C. Bjork, "Decentralisation in education, institutional culture and teacher autonomy in Indonesia," International Review of Education, vol. 50, no. 3-4, pp. 245-262, 2004.

[3] D. Chapman, E. Barcikowski, M. Sowah, E. Gyamera, and G. Woode, "Do communities know best? Testing a premise of educational decentralization: community members' perceptions of their local schools in Ghana," International Journal of Educational Development, vol. 22, no. 2, pp. 181-189, 2002.

[4] H. Walberg, S. Paik, A. Komukai, and K. Freeman, "Decentralisation: an international perspective," in Educational Horizons, pp. 155-166, Winter, 2000.

[5] J. Zajda, "The role of the state in education," International Review of Education, vol. 50, no. 3-4, pp. 199-221, 2004.

[6] C. Dyer and P. Rose, "Decentralisation for educational development? An editorial introduction," Compare, vol. 35, no. 2, pp. 105-113, 2005.

[7] R. Govinda, Decentralisation of Educational Management: Experiences in South Asia, International Institute for Educational Panning, Paris, France, 1997.

[8] M. O'Sullivan, "Reform implementation and the realities within which teachers work: a Namibian case study," Compare, vol. 32, no. 2, pp. 219-237, 2002. 
[9] J. Naidoo, "Managing the improvement of education," in The Challenge of Learning: Improving the Quality of Education in Sub-Saharan Africa, A. M. Verspoor, Ed., pp. 239-267, Association for the Development of Education in Africa, Paris, France, 2005.

[10] K. Bredenberg and N. Dahal, "Can school clustering enhance educational effectiveness? Promises and pitfalls," report, Phnom Penh, Cambodia, 2000.

[11] A. Pellini, "Decentralisation of education in Cambodia: searching for spaces of participation between traditions and modernity," Compare, vol. 35, no. 2, pp. 205-216, 2005.

[12] J. Behrman, A. Deolalikar, and L.-Y. Soon, "Conceptual issues in the role of education decentralisation in promoting effective schooling in Asian developing countries," Economic and Research Department Working Paper 22, Asian Development Bank, Manila, Philippines, 2002.

[13] A. Summers and A. Johnson, "The effects of school-based management plans," in Improving America's Schools: The Role of Incentives, E. Hanushek and D. Jorgenson, Eds., pp. 75-96, Academy Press, Washington, DC, USA, 1996.

[14] R. Khaniya, Teacher Support through Resources Centres: The Nepalese Case, International Institute for Educational Panning, Paris, France, 1997.

[15] G. Carron and A. De Grauwe, Current Issues in Supervision: A Literature Review, International Institute for Educational Planning, Paris, France, 1997.

[16] K. Leithwood and T. Menzies, "Forms and effects of schoolbased management: a review," Educational Policy, vol. 12, no. 3, pp. 325-346, 1998.

[17] N. Angula and S. G. Grant Lewis, "Promoting democratic processes in educational decision making: reflections from Namibia's first 5 years," International Journal of Educational Development, vol. 17, no. 3, pp. 233-249, 1997.

[18] S. Grant Lewis and S. Motala, "Educational de/centralisation and the quest for equity, democracy and quality," in Changing Class: Educational and Social Change in Post-Apartheid South Africa, L. Chisholm, Ed., pp. 115-142, Human Sciences Research Council, Cape Town, South Africa, 2004.

[19] F. Dittmar, J. Mendelson, and V. Ward, The School Cluster System in Namibia, Raison, Windhoek, Namibia, 2002.

[20] H. Pomuti, An analysis of the relationship between clusterbased school managementand teaching in Namibia, Ph.d thesis, University of Pretoria, Pretoria, South Africa, 2009.

[21] K. Mannheim, Ideology and Utopia, Routledge, London, UK, 2002.

[22] C. Cohen, Administering Education in Namibia: The Colonial Period to the Present, Namibia Scientific Society, Windhoek, Namibia, 1994.

[23] E. Weber, "An ambiguous, contested terrain: governance models for a new South African education system," International Journal of Educational Development, vol. 22, no. 6, pp. 617635, 2002. 

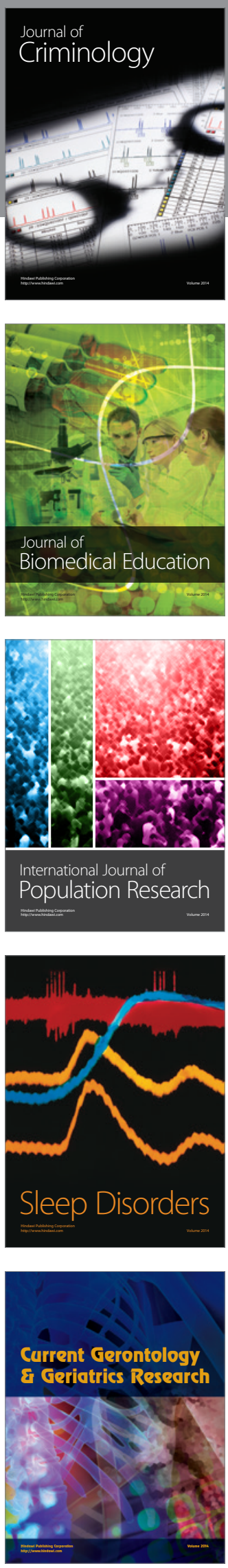
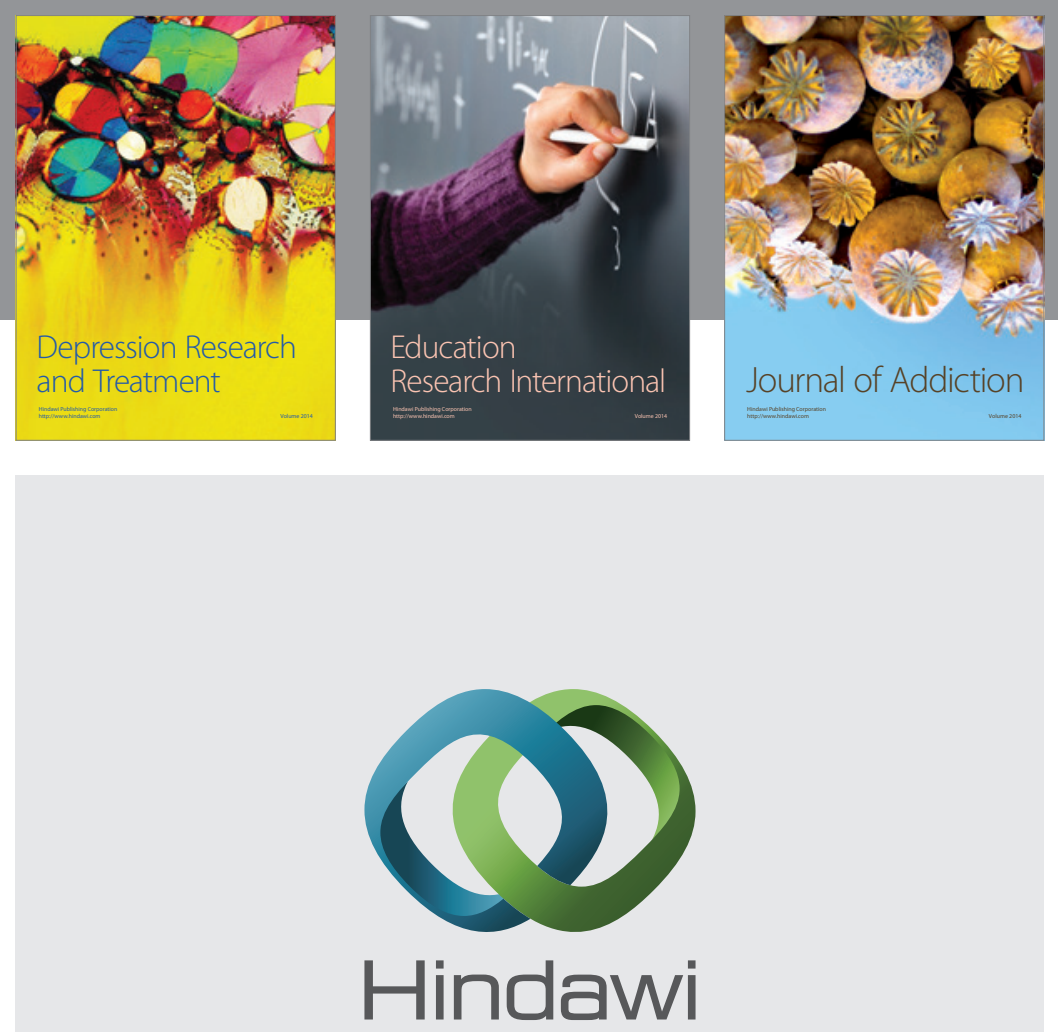

Submit your manuscripts at

http://www.hindawi.com

Child Development Research
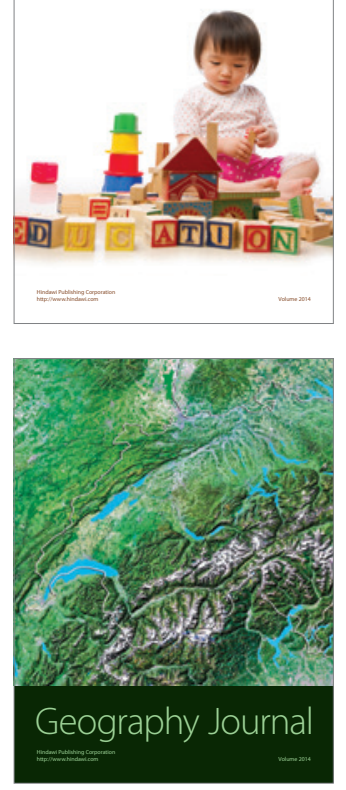

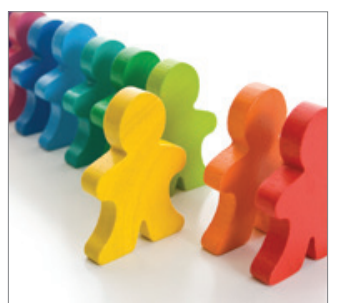

Autism

Research and Treatment
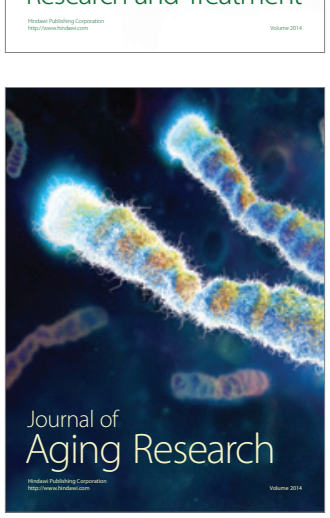
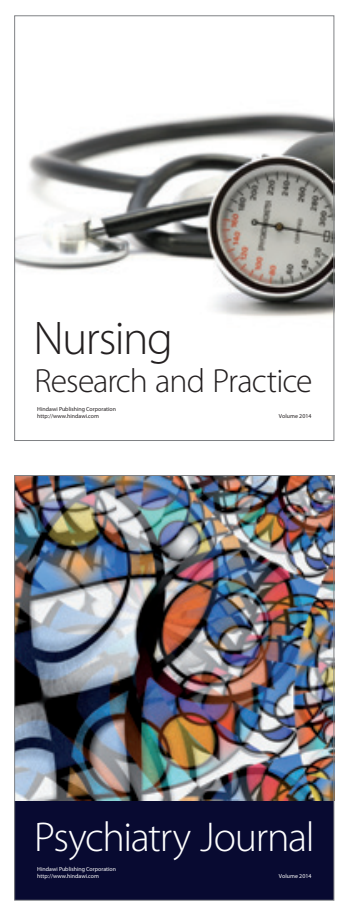
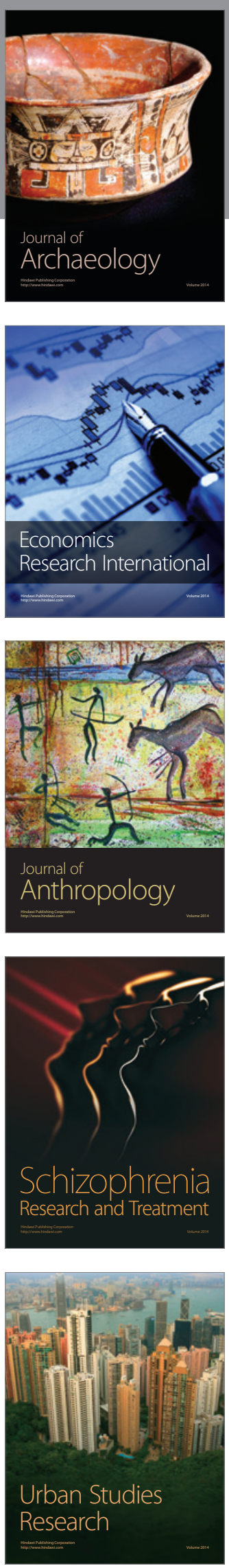